\title{
How spiral computed tomography can be helpful in the evaluation of urinary stones composition?
}

\author{
Shahram Gooran ${ }^{1}$, Zohreh Rohani ${ }^{2}$, Sirvan Akhgar ${ }^{3}$, Mohsen Rajabnia Chenari ${ }^{4}$, Esmaeil Rezghi Maleki ${ }^{5}$, \\ Behzad Narouie ${ }^{5,6^{*}}$ \\ ${ }^{1}$ Urology Research Center, Sina Hospital, Tehran University of Medical Sciences, Tehran, Iran \\ ${ }^{2}$ Department of Radiology, Zahedan University of Medical Sciences, Zahedan, Iran \\ ${ }^{3}$ Zahedan University of Medical Sciences, Zahedan, Iran \\ ${ }^{4}$ Student Research Committee, Zahedan University of Medical Sciences, Zahedan, Iran \\ ${ }^{5}$ Urology and Nephrology Research Center, Department of Urology, Shahid Labbafinejad Medical Center, Shahid Beheshti University of Medical \\ Sciences, Tehran, Iran \\ ${ }^{6}$ Department of Urology, Zahedan University of Medical Sciences, Zahedan, Iran
}

\section{A R T I C L E I N F O}

Article Type:

Original

Article History:

Received: 9 October 2016

Accepted: 2 January 2017

Published online: 20 January 2017

Keywords:

Kidney stones

Computed tomography

Urolithiasis

\begin{abstract}
A B S T R A C T
Introduction: Knowing the composition of a urinary calculus is frequently a key factor in determining its most appropriate management. Helical computed tomography (CT) can provide helpful information on stone size and stone composition.

Objectives: We sought to determine the urinary stone composition by CT characteristics.

Materials and Methods: Since March 2008 till August 2009, 120 renal stones were obtained from patients who had undergone pyelolithotomy or nephrolithotomy at the Imam-Ali hospital, Zahedan, Iran. Stones with the largest diameter more than or equal to $5 \mathrm{~mm}$ were studied. Each calculus was placed inside the chicken lean meat. The radiologist was unaware of the exact chemical composition of the stones. We used independent sample $t$ test for comparison of the absolute Hounsfield unit (HU) values of the different types of calculi.

Results: Of total 120 participated patients, 67 (55.8\%) were male and 53 of them $(44.2 \%)$ were female. The mean age of cases was $35.8 \pm 12.4$ years. According to HU in CT scan and final confirmation with chemical analysis, the calculi were classified into several groups. Of 120 stones, 112 were chemically pure and 8 were mixed. There were 59 calcium oxalate, 27 calcium phosphate, 17 uric acid, 5 struvite, 4 cysteine and 8 mixed stones with variable ratios. In the analysis of the stones, overall difference between densities of the stones was statistically significant $(P<0.001)$.

Conclusion: According to the result of our study, we concluded that the use of non-contrast $\mathrm{CT}$ can be helpful in the prediction of urinary stone composition
\end{abstract}

Implication for health policy/practice/research/medical education:

Mean density of the urinary stones has significant differences. Stone densitometry can be used to differentiate stones from each other. Generally we can state that the use of non-contrast CT and its HU densitometry can be helpful in the prediction of urinary stone composition and it may improve prevention, diagnosis and treatment of urinary stones.

Please cite this paper as: Gooran Sh, Rohani Z, Akhgar S, Rajabnia Chenari M, Rezghi Maleki E, Narouie B. How spiral computed tomography can be helpful in the evaluation of urinary stones composition? J Renal Inj Prev. 2017;6(3):188-191. DOI: $10.15171 /$ jrip.2017.36.

\section{Introduction}

Urinary calculi are a common clinical disorder affecting up to $5 \%$ of the general population (1). In both sexes, the prevalence of renal stone disease has been rising, being estimated that about 5\% of American women and 12\% of men will finally develop a kidney stone during rest of their lifetime (2). Nevertheless, in certain areas of the world, the lifetime risk appears to be even higher as in the Middle East (3). Renal stone disease in children has been heightened awareness (4). Recurrence rates of $50 \%$ after 10 years and $75 \%$ after 20 years have been reported $(5,6)$. Knowing the composition of a urinary calculus 
is frequently a key factor in determining its most appropriate management. Urine $\mathrm{pH}$, urinary crystals, plain radiography, prior stone history, and the presence of urea-splitting organisms are tools currently used to determination of the stone composition (7).

For stone size and stone composition, helical computed tomography (CT) can provide helpful information. Helical CT can reveal stone size more accurately than standard radiography and nephrotomography (8). Several in vitro studies have suggested that spiral CT can extend these tools for determination differences in radio-density among different urinary stones (9-12).

Bellin et al (12) reported prediction of stone composition with 64\%-81\% accuracy, whereas Zarse et al (13) demonstrated that high resolution spiral CT yields unique CT numbers for common types of stones if proper window settings are used to localize homogeneous regions within the stones.

\section{Objectives}

We sought to determine whether the composition of a urinary stone could be predicted by CT characteristics.

\section{Materials and Methods}

Since March 2008 till August 2009, 120 renal stones were obtained from patients who had undergone nephrolithotomy or pyelolithotomy at the Imam Ali hospital, Zahedan, Iran. Stones with the largest diameter more than or equal to $5 \mathrm{~mm}$ were studied. Each calculus was placed inside the chicken lean meat. The radiologist was unaware of the exact chemical composition of the stones.

The calculi were scanned with a G force (Tsx-021) dual detector using $3 \mathrm{~mm}$ thickness scanning at $120 \mathrm{kV}$. The millamperes were kept constant at 240. Three different 1 pixel region of interest Hounsfield unit (HU) measurements were obtained from each stone (one central and two at the periphery). The average of the 3-pixel HU represents the absolute HU for the pure stone. For this report, the average fraction of the outer and inner composition was determined the overall stone composition.

After scanning, all stones were analyzed by the Pastor biomedical laboratory in Zahedan using crystallography, infrared spectrophotometry and polarization microscopy which generated the percentages of the predominant and secondary components. For pure stones one chemical component comprising more than $70 \%$ of the whole were defined.

\section{Ethical issues}

1) The research followed the tenets of the Declaration of Helsinki; 2) informed consent was obtained; and 3) This study was approved by the Ethics Committee of Zahedan University of Medical Sciences.

\section{Statistical analysis}

Statistical analysis was performed by SPSS software (version 17) and results were presented by using chisquare test. For comparison of the absolute HU in CT scan and values of the different types of calculi, independent sample Student's $t$ test was applied. Results were considered significant when $P<0.05$.

Results

Of total 120 patients participated, 67 patients (55.8\%) were male and 53 of them (44.2\%) were female. Gender frequency distribution of urinary stone composition presented in Figures 1 and 2.

According to HU in CT scan and final confirmation with chemical analysis, the calculi were classified into several groups. Of the 120 stones, 112 were chemically pure and 8 were mixed. There were 59 calcium oxalate, 27 calcium phosphate, 17 uric acid, 5 struvite, 4 cystine and 8 mixed stones with variable ratios. In the analysis of stones, the overall difference between densities of the stones was statistically significant $(P=0.001$; Table 1$)$.

\section{Discussion}

Our results showed that the mean density of the stones has significant differences so maybe stone densitometry can be used to differentiate stones from each other. Uric acid stones had a lower density than other types. Uric acid stones can be often indistinguishable from the other stones. In the study of Deveci and colleagues (14), in vitro environment 107 stones were scanned and difference

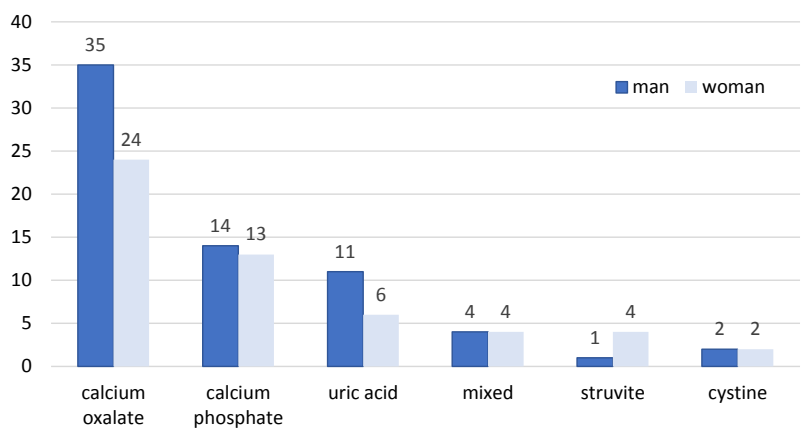

Figure 1. Frequency distribution of urinary stone composition base on gender.

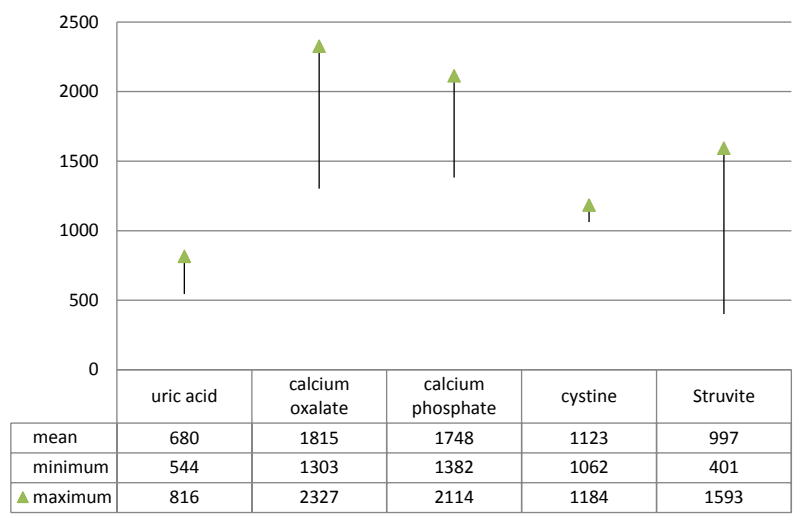

Figure 2. HU (Hounsfield unit) density and stone composition. 
Table 1. Measured CT characteristics of stone ${ }^{a}$

\begin{tabular}{lll}
\hline Stone type & No. & $\begin{array}{l}\text { Absolute CT } \\
\text { value } \pm \text { SD (HU) }\end{array}$ \\
\hline Uric acid & 17 & $680 \pm 136$ \\
Calcium oxalate & 59 & $1815 \pm 512$ \\
Calcium phosphate & 27 & $1748 \pm 366$ \\
Cystine & 4 & $1123 \pm 61$ \\
Struvite & 5 & $997 \pm 596$ \\
\hline a $P<0.0001$ & &
\end{tabular}

between densities of stones was statistically significant $(P<0.001)$. Noticeably, they used $1 \mathrm{~mm}$ cutting in the scanning which is not useful for assessment of flank pain while in our study $3 \mathrm{~mm}$ cutting was used that is consistent with protocol of CT scan for renal stone. Likewise, we used lean meat that is similar to kidney tissue. Hillman and colleagues (15) scanned 36 stones in water environment and could distinguish uric acid stones from struvite and oxalate calcium.

In most studies, uric acid stones are indistinguishable easily from other stone (9-11). Mostafavi and colleagues (11) differentiated easily chemical composition of calcium oxalate, struvite and uric acid stones which was similar to our study. In addition, we assessed cystine and calcium phosphate stones.

Saw and colleagues (16) despite the conclusions based on the thickness of $1 \mathrm{~mm}$, have proposed that scan cutting must be wider than $1 \mathrm{~mm}$ for assessment of urinary tract for stones. They also showed that thickness of cutting effects on analysis of stone density. Thus, we selected $3 \mathrm{~mm}$ cutting as it is more practical. Demirel et al (17) differentiated uric acid, calcium oxalate and struvite stones based on mean HU densities. In their study, uric acid had lowest density and calcium oxalate had highest density but cystine and phosphate calcium were not assessed.

In our study, stone density had not significantly different between men and women $(P=0.32)$. Hence, the patient's gender alone has no effect on the density of stones although this hypothesis requires more detailed studies. Struvite stone has been observed in women more than men that is consistent with other studies (1-3). Urinary tract stone disease is common in the Western world. Non-enhanced $\mathrm{CT}$ is the method of choice for stone diagnosis. However, it has a limited role for stone type predicting. Stone composition is currently determined by postoperative assessment of stone fragments. A noninvasive tool for determination of stone composition would improve patient management (18-20).

\section{Conclusion}

Generally, we can state that the use of non-contrast CT can be helpful in the prediction of urinary stone composition.

\section{Limitations of the study}

We did not follow patients for their future urinary stone formation and metabolic evaluation.

\section{Acknowledgments}

We would like to acknowledge our colleagues in Ali Ebne Abitaleb hospital, departments of Urology and Radiology, Zahedan University of Medical Sciences for their leading suggestions on this manuscript.

\section{Authors' contribution}

SHG and ZR conceived the study and contributed reagents and tools. SA and MRC performed the experiments. $\mathrm{BN}$ and ERM analyzed the data and drafted the final manuscript; all authors read, revised, and approved the final manuscript.

\section{Conflicts of interest}

There were no points of conflicts.

\section{Funding/ Support}

This project was funded by research deputy (Grant \# T/322), Zahedan University of Medical Sciences and extracted from Sirvan Akhgar's residential thesis (Thesis \# $\mathrm{T} / 322)$.

\section{References}

1. Stamatelou KK, Francis ME, Jones CA, Nyberg LM, Curhan GC. Time trends in reported prevalence of kidney stones in the United States: 1976-1994. Kidney Int. 2003;63:1817-23. doi: 10.1046/j.1523-1755.2003.00917.x.

2. Moe OW. Kidney stones: pathophysiology and medical management. Lancet. 2006;367:333-44. doi:10.1016/S01406736(06)68071-9.

3. Pak CYC, Resnick MI, Preminger GM. Ethnic and geographic diversity of stone disease. Urology. 1997;50:5047. doi: 10.1016/S0090-4295(97)00307-5.

4. Heilberg IP, Boim MA, Schor N. Biochemical differences between stone formers and normal subjects. In: Segura J, Conort P, Khoury S, Pak C, Preminger GM, Tolley D, eds. Stone Disease (1st International Consultation on Stone Disease). 21th ed. France: Health Publications; 2003:61-4.

5. Trinchieri A, Ostini F, Nespoli R, Rovera F, Montanari E, Zanetti G. A prospective study of recurrence rate and risk factors for recurrence after a first renal stone. J Urol. 1999;162:27-30. doi: 10.1097/00005392-199907000-00007.

6. Sutherland JW, Parks JH, Coe FL. Recurrence after a single renal stone in a community practice. Miner Electrolyte Metab. 1985;11:267-9.

7. Ramakumar S, Patterson DE, LeRoy AJ, Bender CE, Erickson SB, Wilson DM, et al. Prediction of stone composition from plain radiographs. J Endourol. 1999;13:397-401. doi: 10.1089/end.1999.13.397.

8. Olcott EW, Sommer FG, Napel S. Accuracy of detection and measurement of renal calculi: in vitro comparison of three-dimensional spiral CT, radiography, and nephrotomography. Radiology. 1997;204:19-25. doi: 10.1148/radiology.204.1.9205217.

9. Mitcheson HD, Zamenhof RG, Bankoff MS, Prien EL. Determination of the chemical composition of urinary calculi by computerized tomography. J Urol. 1983;130:8149.

10. Newhouse JH, Prien EL, Amis ES, Dretler SP, Pfister RC. Computed tomographic analysis of urinary calculi. Am J 
Roentgenol. 1984;142:545-8. doi: 10.2214/ajr.142.3.545.

11. Mostafavi MR, Ernst RD, Saltzman B. Accurate determination of chemical composition of urinary calculi by spiral computerized tomography. J Urol. 1998;159:673-5. doi: 10.1016/S0022-5347(01)63698-X.

12. Bellin MF, Renard-Penna R, Conort P, Bissery A, Meric JB, Daudon M, et al. Helical CT evaluation of the chemical composition of urinary tract calculi with a discriminant analysis of CT-attenuation values and density. Eur Radiol. 2004;14:2134-40. doi: 10.1007/s00330-004-2365-6.

13. Zarse CA, McAteer JA, Tann M. Helical computed tomography accurately reports urinary stone composition using attenuation values: in vitro verification using highresolution micro-computed tomography calibrated to fourier transform infrared microspectroscopy. Urology. 2004;63:828-33. doi: 10.1016/j.urology.2003.11.038.

14. Deveci S, Coşkun M, Tekin MI, Peşkircioglu L, Tarhan NC, Ozkardeş H. Spiral computed tomography: role in determination of chemical compositions of pure and mixed urinary stones : an in vitro study. Urology. 2004;64:237-40. doi: 10.1016/j.urology.2004.03.029.

15. Hillman BJ, Drach GW, Tracey P, Gaines JA. Computed tomographic analysis of renal calculi. Am J Roentgenol. 1984;142:549-52. doi: 10.2214/ajr.142.3.549.

16. Saw KC, McAteer JA, Monga AG. Helical CT of urinary calculi: effect of stone composition, stone size, and scan collimation. Am J Roentgenol. 2000;175:329-32. doi: 10.2214/ajr.175.2.1750329.

17. Demirel A, Suma S. The efficacy of non-contrast helical computed tomography in the prediction of urinary stone composition in vivo. J Int Med Res. 2003;31:1-5. doi: 10.1177/147323000303100101.

18. Eliahou R, Hidas G, Duvdevani M, Sosna J. Determination of renal stone composition with dual-energy computed tomography: an emerging application. Semin Ultrasound CT MR. 2010;31:315-20. doi: 10.1053/j.sult.2010.05.002.

19. Assimos DG. Re: Predicting urinary stone composition based on single-energy noncontrast computed tomography: the challenge of cystine. J Urol. 2015;193:170-1. doi: 10.1016/j.juro.2014.10.031.

20. Gücük A, Uyetürk U. Usefulness of hounsfield unit and density in the assessment and treatment of urinary stones. World J Nephrol. 2014;3:282-6. doi: 0.5527/wjn.v3.i4.282.

Copyright $\odot 2017$ The Author(s); Published by Nickan Research Institute. This is an open-access article distributed under the terms of the Creative Commons Attribution License (http://creativecommons.org/licenses/by/4.0), which permits unrestricted use, distribution, and reproduction in any medium, provided the original work is properly cited. 